\title{
LOCAL CORTICOSTEROID INJECTION VERSUS CYRIAX-TYPE PHYSIOTHERAPY FOR TENNIS ELBOW
}

\author{
J. A. N. VERHAAR, G. H. I. M. WALENKAMP, H. VAN \\ MAMEREN, A. D. M. KESTER, A. J. VAN DER LINDEN \\ From the University Hospital, Maastricht, The Netherlands
}

W e performed a prospective, randomised trial on 106 patients to compare the effects of local corticosteroid injections with physiotherapy as advocated by Cyriax in the treatment of tennis elbow. The main outcome measures were the severity of pain, pain provoked by resisted dorsiflexion of the wrist, and patient satisfaction.

At six weeks 22 of 53 patients in the injection group were free from pain compared with only three in the physiotherapy group. In the corticosteroid-treated group 26 patients had no pain on resisted dorsiflexion of the wrist compared with only three in the physiotherapy group. Thirty-five patients who had injections and 14 who had physiotherapy were satisfied with the outcome of treatment at six weeks. At the final assessment there were 18 excellent and 18 good results in the corticosteroid group and one excellent and 12 good results in the physiotherapy group. There was a significant increase in grip strength in both groups but those with injections had a significantly better result.

After one year there were no significant differences between the two groups. Half of the patients, however, had received only the initial treatment, $20 \%$ had had combined therapy and $30 \%$ had had surgery.

We conclude that at six weeks, treatment with corticosteroid injections was more effective than Cyriax physiotherapy and we recommend it because of its rapid action, reduction of pain and absence of side-effects.

J Bone Joint Surg [Br] 1995;77-B:128-32.

Received 1 December 1994; Accepted after revision 27 June 1995

J. A. N. Verhaar, MD, PhD, Professor of Orthopaedic Surgery

University Hospital, Dr Molewaterplein 40, 3015 GD Rotterdam, The Netherlands.

G. H. I. M. Walenkamp, MD, PhD, Associate Professor of Orthopaedic Surgery

A. J. van der Linden, $\mathrm{MD}, \mathrm{PhD}$, Professor of Orthopaedic Surgery University Hospital, PO Box 5800, 6202 AZ Maastricht, The Netherlands.

H. van Mameren, MD, PhD, Anatomist

A. D. M. Kester, PhD, Statistician

University of Limburg, P. de Beyeplein 15, 6229 HA Maastricht, The Netherlands.

Correspondence should be sent to Professor J. A. N. Verhaar.

(C)1996 British Editorial Society of Bone and Joint Surgery 0301-620X/96/11108\$2.00
Conservative treatment of the tennis elbow syndrome lacks any scientific basis (Labelle et al 1990). Local corticosteroid injections and physiotherapy are common treatments. Several authors have reported the effectiveness of the former but after the initial reduction or disappearance of the symptoms some patients have had recurrence of pain (Freeland and Gribble 1954; Murley 1954; Quin and Binks 1954; Young, Ward and Henderson 1954; Bailey and Brock 1957; Day, Govindasamy and Patnaik 1978). In many studies the results of physiotherapy were no better than those of placebo treatment (Devereaux, Hazleman and Thomas 1985; Lundeberg, Haker and Thomas 1987; Chard and Hazleman 1988; Lundeberg, Abrahamsson and Haker 1988).

Cyriax (1936, 1982) claimed substantial success for using local friction in combination with Mills' manipulations. There have been no comparative studies of these forms of treatment.

Our aim was to compare the outcome and side-effects of treatment with local corticosteroids with physiotherapy as described by Cyriax.

\section{PATIENTS AND METHODS}

For one year all patients with tennis elbow referred to the University Hospital, Maastricht were included in our study. The criteria for entry were pain on the lateral side of the elbow, tenderness over the forearm extensor origin, and pain on the lateral epicondyle during resisted dorsiflexion of the wrist with the elbow in full extension. Patients were excluded if they had had a previous operation on the lateral side of the elbow, or had arthritis or allied conditions, neurological disorders of the painful extremity, more than three local corticosteroid injections during the six months before consultation, and if the same elbow had been treated before by Cyriax's methods.

In those with bilateral symptoms only the most painful arm was included. The patients were randomised into two groups using sealed numbered envelopes without strata or blocks. For ethical reasons we did not continue the randomised treatment if the results were unsuccessful.

There were 106 patients (59 men and 47 women) with a mean age of 43 years (SD 9). Physical examination consisted of inspection, measurement of range of movement of the elbow, and assessment of the pain provoked by resisted movement and palpation. The mean duration of the symp- 
Table I. Scoring system for the results of treatment based on the criteria of Verhaar et al (1993)

\begin{tabular}{ll}
\hline Excellent & $\begin{array}{l}\text { Complete relief of pain on the lateral epicondyle } \\
\text { Patient satisfied with the result of treatment } \\
\text { No subjective loss of grip strength } \\
\text { No pain provoked by resisted dorsiflexion of } \\
\text { the wrist } \\
\text { Good } \\
\text { Occasional slight pain on the lateral epicondyle } \\
\text { after strenuous activities } \\
\text { Patient satisfied with the result of treatment } \\
\text { No or slight subjective loss of grip strength } \\
\text { No pain provoked by resisted dorsiflexion of the } \\
\text { wrist } \\
\text { Fair } \\
\text { Discomfort on the lateral epicondyle after } \\
\text { strenuous activities but at a more tolerable level } \\
\text { than before treatment } \\
\text { Patient satisfied or moderately satisfied with the } \\
\text { result of treatment } \\
\text { Slight or moderate subjective loss of grip strength } \\
\text { Slight or moderate pain provoked by resisted } \\
\text { dorsiflexion of the wrist } \\
\text { No decrease of pain on the lateral epicondyle } \\
\text { Patient dissatisfied with the result of treatment } \\
\text { Severe subjective loss of grip strength } \\
\text { Severe pain provoked by resisted dorsiflexion of } \\
\text { the wrist }\end{array}$ \\
Poor
\end{tabular}

toms was 33 weeks. In 11 patients there was some swelling around the lateral epicondyle and in seven limited extension induced by pain on passive or active extension. Ninety-two patients had been treated by their general practitioner, of whom 34 had been given medication, mostly non-steroidal anti-inflammatory agents. An average of one corticosteroid injection had been given (maximum three) and an average of eight physiotherapy treatments, but not using the Cyriax technique.

Local corticosteroid injections. We injected $1 \mathrm{ml}$ of triamcinolone acetate suspension $1 \%$ diluted with $1 \mathrm{ml}$ of lidocaine $1 \%$ into the tendinous origin of the extensor digitorum and extensor carpi radialis brevis muscles. The patients were seen two and four weeks after the start of the treatment and a second or third injection was given if there were persistent symptoms at the two- or four-week followup. Patients were advised not to use the affected arm for any activity which provoked pain during the six weeks of the treatment period.

Physiotherapy according to Cyriax (1936, 1982). Physiotherapy consisted of deep transverse friction over the extensor origin and Mills' manipulations. A total of 12 treatments was given over four weeks, followed by another two weeks of restriction of all painful activities. All physiotherapists were very experienced in the technique.

At follow-up we assessed the occurrence and severity of pain, subjective loss of grip strength, time of return to work and performed provocation tests (resisted movement), local tenderness, localisation of the point of maximal tenderness and grip strength (hand dynamometer). All patients had at least two assessments with the same intervals between the start of treatment and assessment.
Patients were classified as satisfied, moderately satisfied or dissatisfied and the results graded according to the criteria of Verhaar et al (1993) (Table I).

If the treatment had been unsuccessful after six weeks, it was discontinued and a different method chosen. Conservative treatment was considered unsuccessful if the patient still had moderate or severe symptoms and was unsatisfied with the outcome. Patients were reviewed again 52 weeks after the start of the treatment.

Operative treatment was considered for patients with persistent symptoms for more than six months which had not been alleviated by conservative treatment for more than three months. The decision to operate, however, depended also on the individual patient's functional requirements.

Statistical analysis. Differences between the two treatments groups at 0,6 and 52 weeks were tested by the chisquared test for linear trend and differences in the increase of grip strength by two-sample $t$-tests. At 6 and 52 weeks multiple linear regression was used on the log-transformed values for grip strength. For the other outcome variables, multiple polychotomous logistic regression was used to obtain a more accurate evaluation of the results with correction for possible imbalances in the randomisation and to identify other predictors for the outcome at six weeks.

\section{RESULTS}

After six weeks of treatment we reviewed 103 patients; two from the physiotherapy group and one from the injection group were not examined. Of the injection group 20 had been treated with one injection, 17 with two, and 16 with three. At six weeks, the results based on history (Table II) and physical examination (Table III) showed that the injection group had improved significantly better than the physiotherapy group. At one year we found no difference between the groups. Seventeen patients of the steroid group and 14 of the physiotherapy group eventually had operations.

Grip strength. Table IV shows the results. No significant differences were found. The absolute value of the grip strength is known to be related to gender, profession, dominance of the arm, type of sports or hobby, and other variables. The mean grip strength at 0 weeks was lower in the local injection group than in the physiotherapy group and therefore we calculated the increase or decrease in grip strength at six weeks in the painful compared with the control arm (Table V). The increase in the grip strength in the injection group was significantly greater than that in the physiotherapy group.

Patients' assessment and result rating. Overall, $48 \%$ of the patients were satisfied with the improvement after six weeks (Table VI). Satisfaction was lower in the physiotherapy group $(\mathrm{p}<0.001)$. At six weeks, $49(47 \%)$ had a good or excellent result. Eighteen of the injection group and one of the physiotherapy group were completely free from symptoms. 
Table II. Subjective variables at 0,6 and 52 weeks for the physiotherapy group (P) and for the injection group (I)

\begin{tabular}{|c|c|c|c|c|c|c|c|}
\hline & $\mathbf{0}$ & & 6 & & & 52 & \\
\hline & $\overline{\mathbf{P}}$ & I & $\overline{\mathbf{P}}$ & I & p value* & $\overline{\mathbf{P}}$ & I \\
\hline Severity of pain & & & & & & & \\
\hline Absent & 0 & 0 & 3 & 22 & & 16 & 9 \\
\hline Slight & 1 & 2 & 19 & 20 & $<0.001$ & 21 & 26 \\
\hline Moderate & 32 & 30 & 22 & 9 & & 11 & 14 \\
\hline Severe & 20 & 21 & 7 & 1 & & 5 & 4 \\
\hline Occurrence of pain & & & & & & & \\
\hline Never & 0 & 0 & 3 & 22 & & 16 & 10 \\
\hline Seldom & 5 & 4 & 15 & 15 & $<0.001$ & 16 & 23 \\
\hline Regularly & 25 & 22 & 24 & 12 & & 16 & 12 \\
\hline Often/continuously & 23 & 27 & 9 & 3 & & 5 & 8 \\
\hline Subjective loss of grip & & & & & & & \\
\hline Absent & 10 & 6 & 13 & 32 & & 25 & 26 \\
\hline Slight & 11 & 12 & 24 & 13 & $<0.01$ & 18 & 21 \\
\hline Moderate & 25 & 28 & 12 & 5 & & 9 & 6 \\
\hline Severe & 7 & 7 & 2 & 2 & & 1 & 0 \\
\hline Resumption of labour & & & & & & & \\
\hline Resumed & & & 4 & 9 & & 19 & 21 \\
\hline Still working & & & 14 & 15 & $<0.05$ & 8 & 13 \\
\hline Unable to work & & & 13 & 9 & & 6 & 2 \\
\hline Not applicable & & & 20 & 19 & & 20 & 17 \\
\hline Missing & & & 2 & 1 & & & \\
\hline Total & 53 & 53 & 53 & 53 & & 53 & 53 \\
\hline
\end{tabular}

*differences between 0 and 6 weeks

Table III. Results of physical examination at 0,6 and 52 weeks for the physiotherapy group $(\mathrm{P})$ and for the injection group (I)

\begin{tabular}{|c|c|c|c|c|c|c|c|c|}
\hline & \multicolumn{2}{|l|}{$\mathbf{0}$} & \multicolumn{3}{|l|}{6} & \multicolumn{3}{|l|}{52} \\
\hline & $\overline{\mathbf{P}}$ & I & $\overline{\mathbf{P}}$ & I & p value* & $\overline{\mathbf{P}}$ & I & p value \\
\hline \multicolumn{9}{|c|}{ Resisted dorsiflexion of the wrist } \\
\hline Absent & 0 & 0 & 5 & 26 & & 23 & 16 & \\
\hline Slight & 9 & 7 & 24 & 17 & $<0.001$ & 25 & 32 & $<0.05$ \\
\hline Severe & 44 & 46 & 22 & 9 & & 5 & 5 & \\
\hline \multicolumn{9}{|c|}{ Resisted dorsiflexion of middle fingers } \\
\hline Absent & 12 & 6 & 22 & 37 & & 33 & 29 & \\
\hline Slight & 33 & 39 & 23 & 15 & $<0.001$ & 20 & 24 & $<0.05$ \\
\hline Severe & 8 & 8 & 6 & 0 & & 0 & 0 & \\
\hline \multicolumn{9}{|c|}{ Local tenderness } \\
\hline Absent & 0 & 0 & 4 & 26 & & 16 & 14 & \\
\hline Slight & 15 & 9 & 21 & 14 & $<0.001$ & 28 & 30 & $<0.05$ \\
\hline Moderate & 25 & 27 & 21 & 11 & & 9 & 9 & \\
\hline Severe & 13 & 17 & 5 & 1 & & 0 & 0 & \\
\hline Missing & & & 2 & 1 & & & & \\
\hline Total & 53 & 53 & 53 & 53 & & 53 & 53 & \\
\hline
\end{tabular}

*differences between 0 and 6 weeks

Table IV. Mean grip strength $(\mathrm{kg} \pm \mathrm{sD})$ at 0,6 and 52 weeks for the physiotherapy and injection groups

\begin{tabular}{lll}
\hline & Injection & Physiotherapy \\
\hline Painful arm & & \\
$\quad 0$ & $18.4 \pm 9.3$ & $23.5 \pm 13.8$ \\
6 & $29.1 \pm 15.9$ & $25.6 \pm 13.7$ \\
52 & $33.1 \pm 13.5$ & $34.5 \pm 14.6$ \\
Control arm & & \\
$\quad 0$ & $36.3 \pm 13.7$ & $37.8 \pm 14.0$ \\
6 & $34.5 \pm 13.5$ & $37.2 \pm 15.2$ \\
52 & $35.9 \pm 13.1$ & $36.5 \pm 15.7$ \\
\hline
\end{tabular}

Table V. Increase (decrease) in grip strength (kg; mean \pm SD) at 6 and 52 weeks compared with the initial grip strength for the physiotherapy and the injection groups with the elbow in $0^{\circ}$ of extension

\begin{tabular}{lll}
\hline & $\mathbf{6}$ & $\mathbf{5 2}$ \\
\hline Painful arm & & \\
$\quad \begin{array}{l}\text { Physiotherapy } \\
\text { Injection }\end{array}$ & $\begin{array}{l}2.3 \pm 10.6 \\
10.7 \pm 14.9\end{array}$ & $11.0 \pm 13.6$ \\
& $\mathrm{p}=0.0015$ & $\mathrm{p}>0.05$ \\
& & \\
Control arm & & \\
$\quad$ Physiotherapy & $-0.6 \pm 8.7$ & $-0.1 \pm 10.9$ \\
Injection & $-1.8 \pm 5.6$ & $-0.3 \pm 6.8$ \\
& $\mathrm{p}>0.05$ & $\mathrm{p}>0.05$ \\
\hline
\end{tabular}


Table VI. Patients' assessment and result rating at 6 and 52 weeks

\begin{tabular}{|c|c|c|c|c|c|c|}
\hline & \multicolumn{3}{|l|}{6} & \multicolumn{3}{|l|}{52} \\
\hline & $\overline{\mathbf{P}}$ & I & p value & $\overline{\mathbf{P}}$ & I & p value \\
\hline \multicolumn{7}{|l|}{ Satisfaction } \\
\hline Dissatisfied & 26 & 9 & & 10 & 10 & \\
\hline $\begin{array}{l}\text { Moderately } \\
\text { satisfied }\end{array}$ & 11 & 8 & $<0.001$ & 13 & 17 & $<0.05$ \\
\hline Satisfied & 14 & 35 & & 30 & 26 & \\
\hline \multicolumn{7}{|l|}{ Result rating } \\
\hline Excellent & 1 & 18 & & 15 & 12 & \\
\hline Good & 12 & 18 & $<0.001$ & 16 & 22 & $<0.05$ \\
\hline Moderate & 15 & 10 & & 17 & 15 & \\
\hline Poor & 23 & 6 & & 5 & 4 & \\
\hline Missing & 2 & 1 & & 0 & 0 & \\
\hline
\end{tabular}

Side-effects. One of the 53 patients discontinued physiotherapy because of severe pain. No side-effects of either treatment were seen at follow-up after six and 52 weeks. There were no infections after the injections and no skin hypopigmentation.

Additional treatments between 6 and 52 weeks. After the assessment of the results at six weeks several patients needed additional treatment. At six weeks 27 of the Cyriax group did not require further treatment but four of these returned with a recurrence of symptoms; in the injection group 40 did not require further treatment but 16 returned because of recurrent symptoms. Three received treatment with physiotherapy and the other 13 had local corticosteroid injections. Thus, six weeks of treatment sufficed in half of our patients ( 23 in the physiotherapy group and 24 in the corticosteroid group).

Statistical analysis of outcome of treatment at 6 and 52 weeks. Multiple linear and logistic regression showed that treatment was the most important factor determining outcome at six weeks. Patients from the corticosteroid group had a better result than those treated by Cyriax's method. If the patient had cervical symptoms before the start of treatment this was likely to be associated with a poor result from physiotherapy. Local tenderness of the epicondyle was more likely to persist. If at the first consultation, there was more pain on resisted dorsiflexion of the middle finger this was likely to correlate with a better result. No significant relationship with other variables was found. A similar analysis for the outcome of treatment at 52 weeks showed that there were no predictors of the end result of treatment.

\section{DISCUSSION}

Our results showed that after six weeks of treatment there was a significant improvement in the entire group of patients but that corticosteroid injections were better than the Cyriax physiotherapy regimen. The success rate in the injection group (69\%) was somewhat lower than previously reported results. Valtonen (1967) reported a success rate of
$86 \%$ and Hughes and Currey (1969) of 95\%. Day et al (1978) showed that $92 \%$ of their patients improved or were cured with corticosteroid injections. These differences may be explained by different definitions of success. For that reason we have attempted to standardise the criteria of success.

Our results in the physiotherapy group (27\%) are also somewhat lower than the $29 \%$ to $53 \%$ success rate obtained by other authors (Hughes and Currey 1969; Devereaux et al 1985). In our study no other method of physiotherapy was compared with the Cyriax treatment. Our results are similar, however, to those of other types of physiotherapy used by other authors (Devereaux et al 1985; Lundeberg et al 1988; Chard and Hazleman 1989).

None of the outcome variables in our study is free from the possibility of observer bias. Even grip strength is not without bias because it is an indirect measure of pain. We could not blind the study for the patients due to the differences of treatment. The risk of observer bias would have been reduced if an independent observer had seen the patients before and after treatment, but we were unable to organise this.

Pain may be influenced by many factors and is difficult to measure. We therefore used grip strength measured with a hand dynamometer as a more objective indication of the outcome of treatment. Gripping is mainly carried out by the forearm flexors. Power grip, however, requires a fixed wrist joint in $15^{\circ}$ of dorsiflexion (van Gemert 1984). This action of the forearm extensors generates tensile forces at the common extensor origin, which is painful in tennis elbow. Thus, grip-strength measures the severity of pain and may serve as a quantitative measure of the response to treatment (Goldie 1964; Nirschl 1973; Thurtle, Tyler and Cawley 1984).

After an initially successful six weeks of treatment, many patients had recurrence of pain, 34\% in the corticosteroid injection group. Most studies of treatment with steroid injections with a short follow-up have claimed excellent results (Hohl 1961; Valtonen 1967; Hughes and Currey 1969; Clarke and Woodland 1975; Day et al 1978; Nevelos 1980). At six months, however, all reported a high recurrence rate, $66 \%$ in one group of patients. Thus, corticosteroid injections may alleviate the pain in tennis elbow very well, but may not address the cause.

Many physicians regard tennis elbow as a benign selflimiting condition, which improves with or without treatment within 8 to 12 months (Cyriax 1936; Quin and Binks 1954; Bailey and Brock 1957). Our study shows that for a selected group of patients it may be the source of prolonged pain and persistent impairment of activities for many months. The duration of symptoms may exceed one year and the economic consequences for some patients may be very high. Half of our patients were unable to work when they were referred. After one year of treatment $9 \%$ still experienced severe pain and $68 \%$ had intermittent pain; only $23 \%$ were completely free from pain. Our results are 
comparable with those of Binder and Hazleman (1983); after one year of treatment $23 \%$ of their patients had severe pain, $57 \%$ had intermittent pain and $28 \%$ were painfree. It must be stressed that our patients had been referred by general practitioners and therefore were only a selection of all patients with tennis elbow.

The high percentage of patients with symptoms which persisted for longer than one year is disappointing, but the severity of symptoms was significantly reduced after one year of treatment. Many patients with persistent symptoms considered them not to be severe enough to require further treatment. In our series $30 \%$ of patients had operations because of persistent symptoms. This figure seems to be rather high in comparison with other studies in which $5 \%$ to $10 \%$ of patients were treated operatively (Roles and Maudsley 1972). Many of these studies, however, were done in areas in which patients are not obliged to see a general practitioner before hospital referral. These study groups therefore comprise an unselected group of patients with a better prognosis than those referred after failure of treatment by a general practitioner.

One year after the start of treatment we found no differences between our groups. At 52 weeks, $50 \%$ of the entire group of patients had received only the initial treatment prescribed, 30\% had been operated upon and 20\% had received combination therapy. This mixing of treatment

\section{REFERENCES}

Baily RA, Brock BH. Hydrocortisone in tennis elbow: a controlled series. Proc Roy Soc Med 1957;50:389-90.

Binder AI, Hazleman BL. Lateral humeral epicondylitis: a study of natural history and the effect of conservative therapy. $\mathrm{Br} J$ Rheumatol 1983;22:73-6.

Chard MD, Hazleman BL. Pulsed electromagnetic field treatment of chronic lateral humeral epicondylitis. Clin Exp Rheumatol 1988; 6:330-2.

Chard MD, Hazleman BL. Tennis elbow: a reappraisal. Br J Rheumatol 1989;28:186-90.

Clarke AK, Woodland J. Comparison of two steroid preparations used to treat tennis elbow using the hypospray. Rheumatol Rehabil 1975; 14:47-9.

Coonrad RW, Hooper WR. Tennis elbow: its course, natural history, conservative and surgical management. J Bone Joint Surg [Am] 1973;55-A: 1177-82.

Cyriax JH. The pathology and treatment of tennis elbow. J Bone Joint Surg 1936;18:921-40.

Cyriax J. Treatment by manipulation, message and injections. In: Textbook of orthopaedic medicine. 11th ed. London: Balliére Tindall, 1982.

Day BH, Govindasamy N, Patnaik R. Corticosteroid injections in the treatment of tennis elbow. Practitioner 1978;220:459-62.

Devereaux MD, Hazleman BL, Thomas PP. Chronic lateral humeral epicondylitis: a double-blind controlled assessment of pulsed electromagnetic field therapy. Clin Exp Rheumatol 1985;3:333-6.

Freeland DE, Gribble M. Hydrocortisone in tennis elbow. Lancet 1954;II:225-6.

van Gemert JGWA. Arthrodesis of the wrist joint. Acta Orthop Scand 1984;55:Suppl 210, 1-146.

Goldie I. Epicondylitis lateralis humeri (epicondylalgia or tennis elbow): a pathogenetical study. Acta Chir Scand Suppl 1964:339. groups may be the reason for the lack of differences between the groups. The initial treatment was not found to influence the outcome after one year.

If all methods of treatment for a disorder are equally effective, the procedure of choice should be the one which is the least invasive, least expensive and most time-efficient (Coonrad and Hooper 1973). Our study showed that local corticosteroid injections gave better pain relief in a shorter time than the Cyriax physiotherapy method. The high recurrence rate after corticosteroid injections, however, suggests that the effect is transient and produces only symptomatic relief. Injections were more time-efficient than physiotherapy; there were two additional visits to the outpatient clinic in the injection group compared with 12 visits to the physiotherapy department. No important sideeffects of either method were found.

Because of the reduced number of hospital visits, the satisfactory pain relief and the lack of side-effects we prefer corticosteroid injections as treatment in patients in whom rest alone does not give adequate relief. After six weeks, corticosteroid injections were found to be more effective than the Cyriax treatment although their healing effect is uncertain.

No benefits in any form have been received or will be received from a commercial party related directly or indirectly to the subject of this article.

Hohl M. Epicondylitis: tennis elbow. Clin Orthop 1961;19:232-8.

Hughes GR, Currey HL. Hypospray treatment of tennis elbow. Ann Rheum Dis 1969;28:58-62.

Labelle H, Fallaha M, Newman N, Rivard C-H, Guibert R. The treatment of tennis elbow: a critical review of the literature. $J$ Bone Joint Surg [Br] 1990;72-B:536.

Lundeberg T, Abrahamsson P, Haker E. A comparative study of continuous ultrasound, placebo ultrasound and rest in epicondylalgia. Scand J Rehabil Med 1988;20:99-101.

Lundeberg T, Haker E, Thomas M. Effect of laser versus placebo in tennis elbow. Scand J Rehabil Med 1987;19:135-8.

Murley AH. Tennis-elbow treated with hydrocortisone acetate. Lancet 1954;II:223-5.

Nevelos AB. The treatment of tennis elbow with triamcinolone acetonide. Curr Med Res Opin 1980;6:507-9.

Nirschl RP. Tennis elbow. Orthop Clin North Am 1973;4:787-800.

Quin CE, Binks FA. Tennis-elbow (epicondylalgia externa): treatment with hydrocortisone. Lancet 1954;II:221-3.

Roles NC, Maudsley RH. Radial tunnel syndrome: resistant tennis elbow as a nerve entrapment. J Bone Joint Surg [Br] 1972;54-B:499-508.

Thurtle OA, Tyler AK, Cawley MI. Grip strength as a measure of response to treatment for lateral epicondylitis. $\mathrm{Br} J$ Rheumatol 1984;23:154-5.

Valtonen EJ. Methylprednisolone acetate in the management of periarthritis of the shoulder and external humeral epicondylitis resistant to physical therapy. Ann Med Intern Fenn 1967;56:61-3.

Verhaar JAN, Walenkamp G, Kester A, Van Mameren H, Van der Linden T. Lateral extensor release for tennis elbow: a prospective longterm follow-up study. J Bone Joint Surg [Am] 1993;75-A:1034-43.

Young HH, Ward LE, Henderson ED. The use of hydrocortisone acetate: (compound $\mathrm{F}$ acetate) in the treatment of some common orthopaedic conditions. J Bone Joint Surg [Am] 1954;36-A:603-9. 